\title{
Reversible multiplexing for optical information recording, erasing, and reading-out in photochromic $\mathrm{BaMgSiO}_{4}: \mathrm{Bi}^{3+}$ luminescence ceramics
}

\author{
Youtao Ren ${ }^{1}$, Zhengwen Yang ${ }^{1 *}$, Yuehui Wang ${ }^{2}$, Mingjun $\mathrm{Li}^{1}$, Jianbei Qiu ${ }^{1}$, Zhiguo Song ${ }^{1}$, Jie $\mathrm{Yu}^{1^{*}}$, \\ Asad Ullah ${ }^{1}$ and Imran Khan ${ }^{1}$
}

\begin{abstract}
Optical data storage technology has many advantages over the traditional solid-state and magnetic storage technology, such as low cost, multi-dimensional storage, and rewritable capability. Therefore, the optical data storage technology has been in increasing demand for optical storage media. Herein, the photochromic and photoluminescence properties of $\mathrm{BaMgSiO}_{4}: \mathrm{Bi}^{3+}$ ceramics were investigated. The BaMgSiO4: $\mathrm{Bi}^{3+}$ ceramics showed reversible photochromism from gray to pink upon alternating the $254 \mathrm{~nm}$ ultraviolet light and $532 \mathrm{~nm}$ laser irradiation. This is caused by the electron trapping and de-trapping in the oxygen vacancies of the $\mathrm{BaMgSiO}_{4}: \mathrm{Bi}^{3+}$ host. This reversible behavior of photochromism was applied to fabricate different patterns on the surface of the $\mathrm{BaMgSiO}_{4}: \mathrm{Bi}^{3+}$ ceramics, which exhibited the reversible dual-mode optical information recording and erasing abilities. The photoluminescence reversible modulation of the $\mathrm{BaMgSiO}_{4}: \mathrm{Bi}^{3+}$ ceramics was obtained through the photochromic phenomenon. This modification behavior of luminescence could be applied to read-out the recording information in the $\mathrm{BaMgSiO}_{4}: \mathrm{Bi}^{3+}$ ceramics. The coloration and bleaching of $\mathrm{BaMgSiO}_{4}: \mathrm{Bi}^{3+}$ ceramics were dependent on the time of light stimulation, which facilitated multiplexing encoding. This photoluminescence and photochromism multiplexing of the $\mathrm{BaMgSiO}_{4}: \mathrm{Bi}^{3+}$ ceramics enhanced the optical data storage capability.
\end{abstract}

Keywords: $\mathrm{BaMgSiO}_{4}: \mathrm{Bi}^{3+}$ ceramic, photochromism, photoluminescence, reversible modification

\section{INTRODUCTION}

With the digitizing and exploding field of information data, the storage life, storage density, and access rate of information data are significantly improved. Optical data storage technology has many advantages such as high storage density, low cost, long storage life, and noncontact writing and reading capabilities. In contrast to the traditional solid-state and magnetic storage technology, these advantages have increased the application of optical data-storage technology for optical storage media [1-6]. Despite the tremendous progress, the optical storage technology is challenged by storage capacity because of the limitation of optical diffraction $[7,8]$. To improve the storage capacity, multiplexing the information storage is required [9-12]. Photochromism is always accompanied by the reversible change of chemical substances between two states upon light stimulation, which can switch the absorption property of materials [13-20]. The " 0 " or " 1 " digital code can be represented by each state, corresponding to "off" or "on" states. These "off" and "on" characteristics of photochromism promote the potential applications in many fields such as high-density optical memory and optical switches [21-26]. Moreover, the photochromic property was dependent on the time of light stimulation, facilitating multiplexed encoding [2729]. Thus, the information-storage capacity could be improved based on the photochromic reaction. At present, various organic photochromic optical storage materials such as diarylethene derivatives have been successfully developed [1,30-35]. However, due to their poor thermal reversibility and fatigue resistance, the use of most diarylethenes as the optical storage materials is challenging [36-39]. Therefore, suitable photochromic materials must be investigated to facilitate their application for optical storage.

In contrast to organic photochromic materials, inorganic photochromic materials have many advantages

${ }^{1}$ College of Materials Science and Engineering, Kunming University of Science and Technology, Kunming 650093, China

${ }^{2}$ Department of Materials and Food, University of Electronic Science and Technology of China Zhongshan Institute, Zhongshan 528402, China

*Corresponding authors (emails: yangzw@kmust.edu.cn (Yang Z); yujieone@163.com (Yu J)) 
such as excellent mechanical strength and chemical and thermal stabilities [40,41]. Various inorganic photochromic materials such as metal oxides $\left(\mathrm{MoO}_{3}, \mathrm{WO}_{3}\right.$, and $\left.\mathrm{V}_{2} \mathrm{O}_{5}\right)$, ferroelectrics $\left(\mathrm{Na}_{0.5} \mathrm{Bi}_{2.5} \mathrm{Nb}_{2} \mathrm{O}_{9}\right.$ and $\left.\mathrm{Bi}_{4} \mathrm{Ti}_{3} \mathrm{O}_{12}\right)$, and other robust oxides $\left(\mathrm{Mg}_{2} \mathrm{SnO}_{4}\right.$ and $\left.\mathrm{Sr}_{2} \mathrm{SnO}_{4}\right)$ have been developed [15,42-46]. Among inorganic photochromic materials, metal oxides suffer from a slow response time and a poor reversibility [25,47]. Ferroelectrics and robust oxides are more suitable as optical storage materials because of their relatively fast response time and good reversibility. However, thermal bleaching may be required for most of the ferroelectrics and robust oxides such as $\mathrm{Na}_{0.5} \mathrm{Bi}_{2.5} \mathrm{Nb}_{2} \mathrm{O}_{9}, \mathrm{Na}_{0.5} \mathrm{Bi}_{0.5} \mathrm{TiO}_{3}, \mathrm{Mg}_{2} \mathrm{SnO}_{4}, \mathrm{Sr}_{2} \mathrm{SnO}_{4}$, and $\mathrm{Bi}_{4} \mathrm{Ti}_{3} \mathrm{O}_{12}[15,48,49]$. Light-induced coloring and bleaching are particularly attractive in actual applications. Therefore, development of inorganic photochromic materials with the appropriate light-induced coloring and bleaching properties is necessary for the realization of their optical storage applications.

Inorganic materials doped with rare-earth ions exhibit unique luminescence property. This property can be reversibly modified based on their photochromic reaction [14-16,44]. Different luminescence intensities provide an interesting opportunity to enhance the optical storage potential of the photochromic luminescent materials [50]. Recently, the bismuth ion was extensively used as an active luminescence center [51-55]. In contrast to the rare-earth ions, the bismuth ion has many advantages such as low cost. However, to the best of our knowledge, no reversible luminescence modification of the bismuthion-doped phosphors has been reported. $\mathrm{BaMgSiO}_{4}$ has the tridymite crystal structure with a $P 63$ space group. The three-dimensional crystal structure of $\mathrm{BaMgSiO}_{4}$ is connected by the $\mathrm{SiO}_{4}$ tetrahedrons by sharing their corners. Recently, the photoluminescence of rare-earthion-doped $\mathrm{BaMgSiO}_{4}$, exhibiting the white light emission or phosphorescence properties, was investigated [56,57]. In this study, $\mathrm{BaMgSiO}_{4}: \mathrm{Bi}^{3+}$ ceramics were prepared. The photochromic-induced photoluminescence reversible modulation of $\mathrm{BaMgSiO}_{4}: \mathrm{Bi}^{3+}$ ceramics was investigated in detail. This reversible modification behavior of photochromism and luminescence was applied to fabricate the patterns on the surface of the $\mathrm{BaMgSiO}_{4}: \mathrm{Bi}^{3+}$ ceramics. These ceramics exhibited the multiplexing ability of reversible optical information recording, erasing, and reading-out.

\section{EXPERIMENTAL}

$\mathrm{BaMgSiO}_{4}: x$ mol$\% \mathrm{Bi}^{3+}(x=0.5,0.75,1,1.5$, and 2$)$ ceramics were prepared by using magnesium oxide $(\mathrm{MgO}$,
99.99\%), barium carbonate $\left(\mathrm{BaCO}_{3}, 99 \%\right)$, silicon dioxide $\left(\mathrm{SiO}_{2}, 99.99 \%\right)$, and bismuth oxide $\left(\mathrm{Bi}_{2} \mathrm{O}_{3}, 99.99 \%\right)$ as raw materials, and $10 \% \mathrm{H}_{3} \mathrm{BO}_{3}$ was added as the fluxing agent. Stoichiometric raw materials were mixed in an agate mortar. The mixed powder was pressed into disk, placed in a tubular furnace and sintered at 1350,1300 , or $1250^{\circ} \mathrm{C}$ in a reducing atmosphere $\left(95 \% \mathrm{~N}_{2}+5 \% \mathrm{H}_{2}\right)$ for $5 \mathrm{~h}$. After sintering, the diameter of all the $\mathrm{BaMgSiO}_{4}: x \mathrm{~mol} \% \mathrm{Bi}^{3+}$ ceramic was about $14 \mathrm{~mm}$. The coloration of $\mathrm{BaMgSiO}_{4}$ : $x$ mol\% $\mathrm{Bi}^{3+}$ ceramics was carried out under the $254 \mathrm{~nm}$ ultraviolet light irradiation (ZF-2 Shanghai Anting) for different times with a power density of $0.21 \mathrm{~W} \mathrm{~cm}^{-2}$. The fading of $\mathrm{BaMgSiO}_{4}: x$ mol\% $\mathrm{Bi}^{3+}$ ceramics was studied upon the $532 \mathrm{~nm}$ laser (VD-VII DPSS LASER Jilin Changchun) irradiation with a power density of $380 \mathrm{~mW} \mathrm{~cm}^{-2}$ for various times. The spot size of the $532 \mathrm{~nm}$ laser irradiation is $\sim 5 \mathrm{~mm}$ in diameter.

The crystallinity and phase structure of the $\mathrm{BaMgSiO}_{4}$ : $x \mathrm{~mol} \% \mathrm{Bi}^{3+}$ ceramics prepared at different temperatures were investigated by the X-ray powder diffraction (XRD, Brucker D8 ADVANCE). Field emission scanning electron microscopy (FE-SEM) was used to observe the morphology of the $\mathrm{BaMgSiO}_{4}: x \mathrm{~mol} \% \mathrm{Bi}^{3+}$ ceramics (QUANTA 650). The thermoluminescence (TL) spectra of ceramics irradiated by $254 \mathrm{~nm}$ ultraviolet light for various times were measured by an FJ-427A1 thermoluminescent meter at a heating rate of $1^{\circ} \mathrm{C} \mathrm{s}^{-1}$. The $\mathrm{U}$ 4100 spectrophotometer with an integrated sphere was used to measure the reflectance spectra of $\mathrm{BaMgSiO}_{4}: \mathrm{Bi}^{3+}$ ceramics. The spectrophotometer (HITACHIU-F-7000) was used to measure the emission and excitation spectra of $\mathrm{BaMgSiO}_{4}: \mathrm{Bi}^{3+}$ ceramics. The electron paramagnetic resonance (EPR) spectrometer (Bruker X-band A300-6/1) was used to measure the oxygen vacancies in the $\mathrm{BaMg}$ $\mathrm{SiO}_{4}: \mathrm{Bi}^{3+}$ ceramics.

\section{RESULTS}

Fig. la presents the XRD patterns of $\mathrm{BaMgSiO}_{4}$ : $x \mathrm{~mol} \% \mathrm{Bi}^{3+}(x=0.5,0.75,1,1.5$ and 2$)$ ceramics prepared at $1350^{\circ} \mathrm{C}$. The pure $\mathrm{BaMgSiO}_{4}: x \mathrm{~mol} \% \mathrm{Bi}^{3+}$ ceramics are classified by the concentration of $\mathrm{Bi}^{3+}$ doping. The main XRD peak shifts gradually to a larger degree with the increasing $\mathrm{Bi}^{3+}$ doping concentration, as shown in Fig. 1a. The radii of $\mathrm{Bi}^{3+}$ and $\mathrm{Ba}^{2+}$ are $\sim 1.03$ and $1.35 \AA$, respectively. The $\mathrm{Bi}^{3+}$ may occupy the $\mathrm{Ba}^{2+}$ sites in the $\mathrm{BaMgSiO}_{4}$ host. The redshift of XRD peaks is due to the crystal lattice shrinkage induced by the cation substitution of $\mathrm{Ba}^{2+}$ with $\mathrm{Bi}^{3+}$. The excitation spectrum of $\mathrm{BaMgSiO}_{4}: 1 \mathrm{~mol} \% \mathrm{Bi}^{3+}$ monitored at $510 \mathrm{~nm}$ is shown in Fig. 1b. A broad excitation peak centered at $346 \mathrm{~nm}$, 

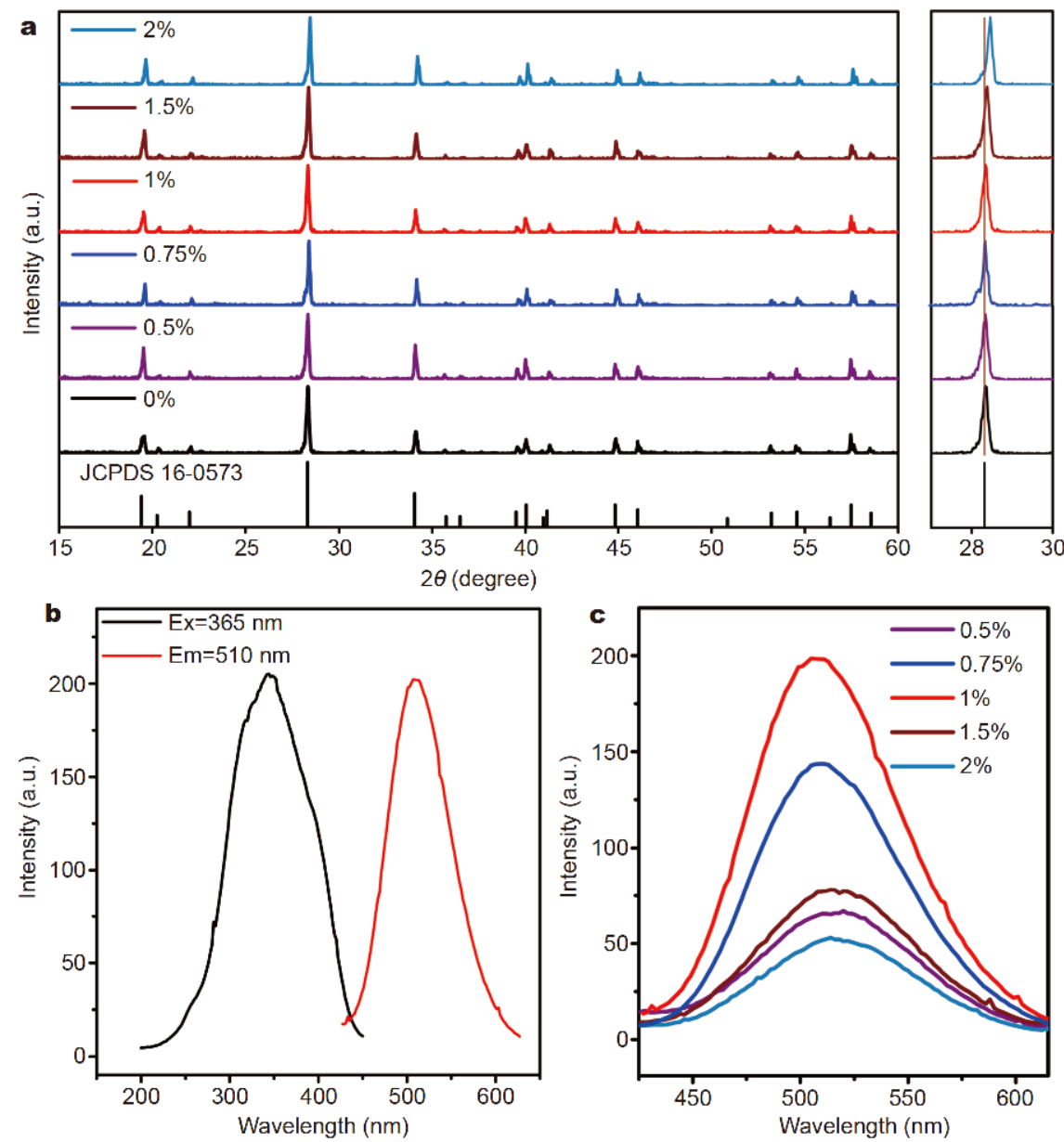

Figure 1 (a) $\mathrm{XRD}$ patterns of $\mathrm{BaMgSiO}_{4}: x$ mol\% $\mathrm{Bi}^{3+}\left(x=0,0.5,0.75,1,1.5\right.$ and 2) ceramics prepared at $1350^{\circ} \mathrm{C}$; (b) excitation spectrum measured at $510 \mathrm{~nm}$ emission of $\mathrm{BaMgSiO}_{4}: 1 \mathrm{~mol} \% \mathrm{Bi}^{3+}$; (c) luminescence spectra of $\mathrm{BaMgSiO}_{4}: x$ mol\% $\mathrm{Bi}^{3+}(x=0,0.5,0.75,1,1.5$ and 2$)$ ceramics upon the $365 \mathrm{~nm}$ excitation.

ranging from 250 to $450 \mathrm{~nm}$ was observed. The broad excitation peak of $\mathrm{Bi}^{3+}$ is advantageous for the excitation of $\mathrm{BaMgSiO}_{4}: \mathrm{Bi}^{3+}$ ceramic. The luminescence spectra of $\mathrm{BaMgSiO}_{4}: x \mathrm{~mol} \% \mathrm{Bi}^{3+}(x=0.5,0.75,1,1.5$, and 2$)$ ceramics upon $346 \mathrm{~nm}$ excitation are shown in Fig. S1. The luminescence property of the $\mathrm{BaMgSiO}_{4}: \mathrm{Bi}^{3+}$ ceramic has no significant change upon the excitation wavelength of 365 or $346 \mathrm{~nm}$. It can be seen from Fig. 1c that the luminescence intensity first increases with the increase of the doping concentration of $\mathrm{Bi}^{3+}$. When the doping concentration of $\mathrm{Bi}^{3+}$ is higher than $1 \mathrm{~mol} \%$, the luminescence intensity of $\mathrm{BaMgSiO}_{4}: \mathrm{Bi}^{3+}$ ceramic decreases, due to the high-concentration quenching effect. Considering the excitation wavelength, the optimal doping concentration is $1 \mathrm{~mol} \%$. In order to achieve the commercial specifications for the $\mathrm{BaMgSiO}_{4}: \mathrm{Bi}^{3+}$ ceramics, in the next section, the $365 \mathrm{~nm}$ UV lamp was applied to excite the ceramics.

The $\mathrm{BaMgSiO}_{4}: 1 \mathrm{~mol} \% \mathrm{Bi}^{3+}$ ceramics prepared at 1400 , 1350,1300 , and $1250^{\circ} \mathrm{C}$, are denoted as BMSO-1400, BMSO-1350, BMSO-1300, and BMSO-1250, respectively. Fig. 2a exhibits the XRD patterns of BMSO-1400, BMSO1350 , BMSO-1300, and BMSO-1250. The sintering temperature has an influence on the phase structures of $\mathrm{BaMgSiO}_{4}: 1 \mathrm{~mol} \% \mathrm{Bi}^{3+}$ ceramics. The hexagonal phase $\mathrm{BaMgSiO}_{4}: 1 \mathrm{~mol} \% \mathrm{Bi}^{3+}$ ceramics was obtained, and a small amount of miscellaneous phase appeared in the BMSO-1400. Pure phase of $\mathrm{BaMgSiO}_{4}: 1 \mathrm{~mol} \% \mathrm{Bi}^{3+}$ ceramics in the BMSO-1350, BMSO-1300 and BMSO-1250 ceramics was obtained based on the JCPDS Card 16-0573.

Fig. $2 b-d$ show the surface FE-SEM images of the pure phase BMSO-1350, BMSO-1300, and BMSO-1250 ceramics, with compact structures. The particle sizes of BMSO-1350, BMSO-1300, and BMSO-1250 are 8.75, 

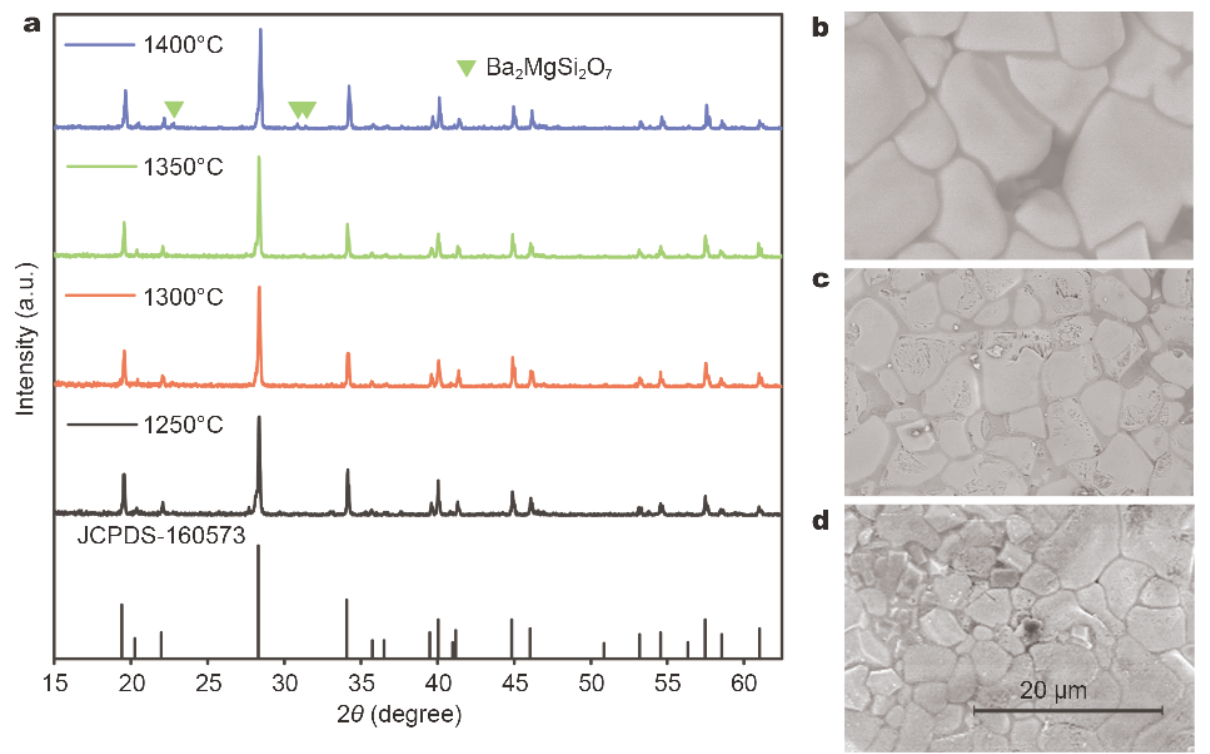

Figure 2 (a) XRD patterns of BMSO-1400, BMSO-1350, BMSO-1300 and BMSO-1250. FE-SEM images of the surface of BMSO-1350 (b), BMSO$1300(\mathrm{c})$, and BMSO-1250 (d).

4.52, and $2.67 \mu \mathrm{m}$, respectively. The size of $\mathrm{BaMgSiO}_{4}$ : $1 \mathrm{~mol} \% \mathrm{Bi}^{3+}$ particles increases with the increase of the sintering temperature.

Fig. 3a-c present the diffuse reflectance spectra and corresponding photos of BMSO-1350, BMSO-1300, and BMSO- 1250 before and after $254 \mathrm{~nm}$ UV light stimulation for $16 \mathrm{~min}$. The color of BMSO-1350, BMSO-1300, and BMSO-1250 ceramics changed from gray to pink as the sintering temperature increased, and a new absorption band at $520 \mathrm{~nm}$ in the region of $450-600 \mathrm{~nm}$ was observed upon the $254 \mathrm{~nm}$ UV light irradiation for $16 \mathrm{~min}$. With an increase in the sintering temperature, the absorption intensity of $520 \mathrm{~nm}$ increased and the pink color deepened, as shown in Fig. 3. Fig. S2 presents the XRD patterns of the pink BMSO-1350, BMSO-1300, and BMSO-1250 ceramics after the photochromism, exhibiting no phase change. The results demonstrate that the photochromism of BMSO-1350, BMSO-1300, and BMSO-1250 ceramics is not due to the phase change. The defects such as $\mathrm{V}_{\mathrm{Ba}}, \mathrm{V}^{\prime \prime}{ }_{\mathrm{Mg}}$ and $\mathrm{V}_{\mathrm{O}}$ can be generated in the $\mathrm{BaMgSiO}_{4}: 1 \mathrm{~mol} \% \mathrm{Bi}^{3+}$ ceramics. Fig. $3 \mathrm{~d}$ presents the EPR spectra of BMSO-1350, BMSO-1300, and BMSO-1250 ceramics, showing an EPR peak located at 1.995 of oxygen vacancies. Fig. 3e exhibits the TL spectra of BMSO1350, BMSO-1300, and BMSO-1250 upon the $254 \mathrm{~nm}$ light irradiation for $16 \mathrm{~min}$, exhibiting two TL peaks at 90 and $140^{\circ} \mathrm{C}$. These results further indicate that defects such as oxygen vacancies are indeed formed in the $\mathrm{BaMgSiO}_{4}$ : $1 \mathrm{~mol} \% \mathrm{Bi}^{3+}$ ceramics. Fig. 3f presents the coloration mechanism of $\mathrm{BaMgSiO}_{4}: 1 \mathrm{~mol} \% \mathrm{Bi}^{3+}$ ceramics. The electrons located at the valence band in the $\mathrm{BaMgSiO}_{4}$ host jump to the conduction band during the $254 \mathrm{~nm}$ UV irradiation. The electrons in the conduction band are captured by the oxygen vacancies, and $\mathrm{F}$ color centers are formed. Thus, the color change of $\mathrm{BaMgSiO}_{4}: 1 \mathrm{~mol} \% \mathrm{Bi}^{3+}$ ceramics from gray to pink is observed. As exhibited in Fig. 3d, e, the TL and EPR intensities increase with the increase of the sintering temperature, indicating that more defects are formed at the high temperature. Thus, better photochromic properties are achieved in the BMSO- 1350 ceramic prepared at $1350^{\circ} \mathrm{C}$. However, the photochromic property decreases when the temperature increases to $1400^{\circ} \mathrm{C}$ as shown in Fig. S3, which may be due to the impure phase.

The influence of the irradiation time on the photochromic properties of BMSO-1350 was also investigated. As shown in Fig. 4a, the color deepens and the absorption intensity at $520 \mathrm{~nm}$ increases with an increase in the irradiation time. Fig. $4 \mathrm{~b}$ illustrates the TL intensity change of BMSO-1350 as a function of the irradiation time. The increase in the TL intensity was observed with prolonged irradiation time (at $254 \mathrm{~nm}$ ), suggesting that more electrons generated in the conduction band were captured by the defects. Thus, the photochromic enhancement of the BMSO-1350 was obtained at the optimal coloration time of $\sim 16 \mathrm{~min}$. The bleaching of the BMSO-1350 after irradiation $(254 \mathrm{~nm})$ for 16 min was investigated upon the irradiation with a $532 \mathrm{~nm}$ laser $\left(380 \mathrm{~mW} \mathrm{~cm}^{-2}\right)$ for var- 

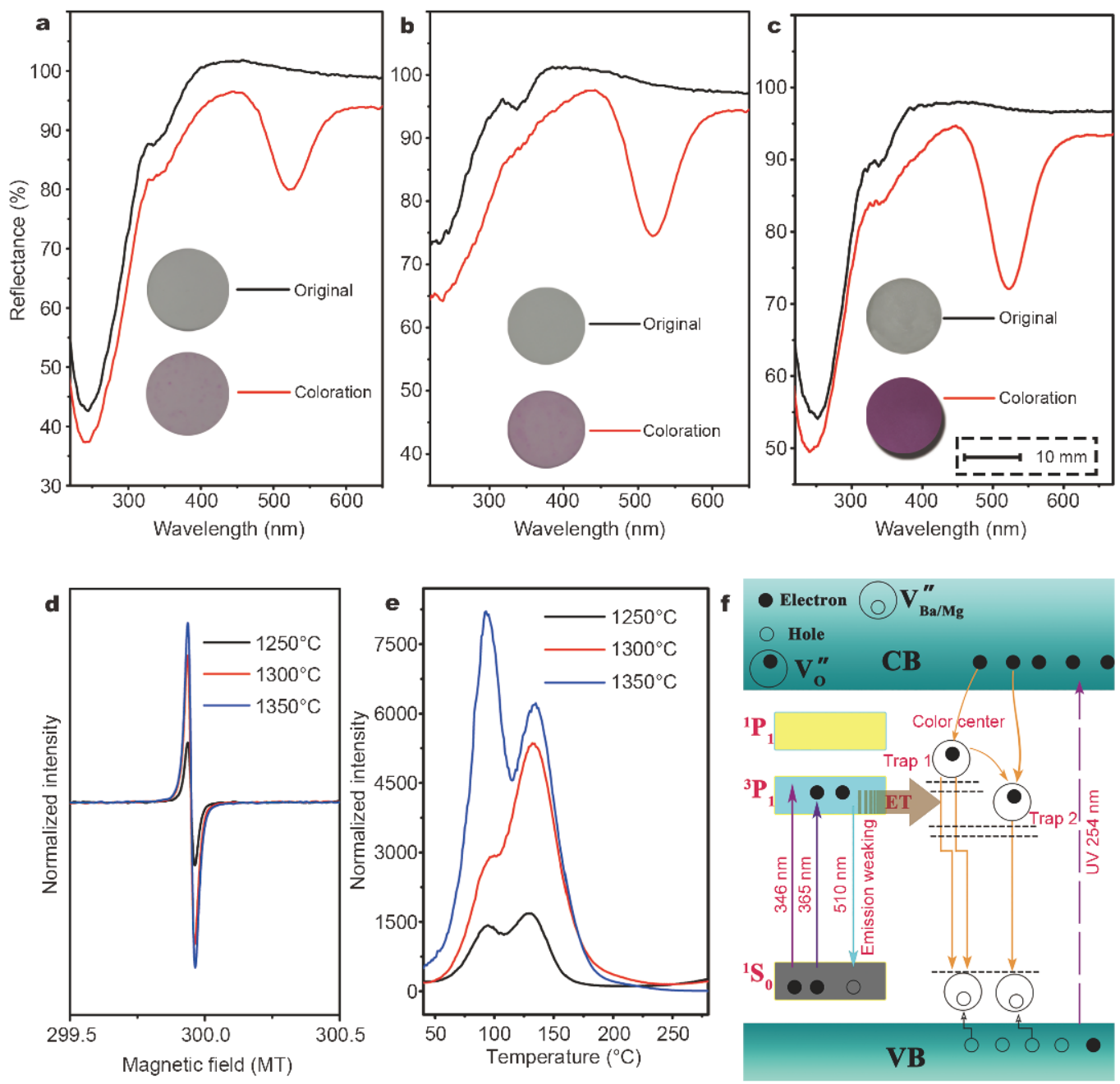

Figure 3 Diffuse reflectance spectra and corresponding photos of BMSO-1250 (a), BMSO-1300 (b) and BMSO-1350 (c) before and after $254 \mathrm{~nm}$ UV light stimulation for $16 \mathrm{~min}$; (d) the EPR spectra of the BMSO-1350, BMSO-1300 and BMSO-1250 without light irradiation; (e) the TL spectra of the BMSO-1350, BMSO-1300 and BMSO-1250 after the $254 \mathrm{~nm}$ UV light irradiation for $16 \mathrm{~min}$; (f) the coloration and discoloration mechanism of the samples.

ious times, as shown in Fig. 4c. The decrease in the $520 \mathrm{~nm}$ absorption intensity and the color fading was observed with an increase in the $532 \mathrm{~nm}$ laser irradiation time. After the $532 \mathrm{~nm}$ laser irradiation for $20 \mathrm{~min}$, the color and absorption intensity returned to the initial state. The $532 \mathrm{~nm}$ laser irradiation could result in a release of electrons in the defect levels, which recombined with the holes captured by the defects of $\mathrm{V}^{\prime \prime}{ }_{\mathrm{Ba}}$ and $\mathrm{V}^{\prime \prime}{ }_{\mathrm{Mg}}$, as shown in Fig. 3f. Thus, the color of BMSO-1350 ceramic faded. The electron release can be demonstrated by the TL spectra. The pink BMSO-1350 ceramic was irradiated by the $532 \mathrm{~nm}$ laser for various times, as shown in Fig. $4 \mathrm{~d}$. The TL intensity decreased with prolongation of the $532 \mathrm{~nm}$ laser irradiation time, suggesting that the number of electrons in the defect levels gradually decreased.

The photochromic reversibility of BMSO-1350 was investigated by alternating the irradiation between the $254 \mathrm{~nm}$ light for $16 \mathrm{~min}$ and the $532 \mathrm{~nm}$ laser for $20 \mathrm{~min}$, as shown in Fig. 5. This figure shows a good and reversible photochromic property between gray and pink after seven cycles. This result indicates that the BaMg$\mathrm{SiO}_{4}: \mathrm{Bi}^{3+}$ ceramics may be viable as optical storage media. The BMSO-1350 ceramic was covered by a mask with sunflower or heart patterns, then irradiated with the $254 \mathrm{~nm}$ light for $16 \mathrm{~min}$. The pink information patterns with gray background formed on the surface of BMSO1350 ceramic (Process (1)), as shown in Fig. 5b. It is noted that when the color of BMSO-1350 ceramic was com- 

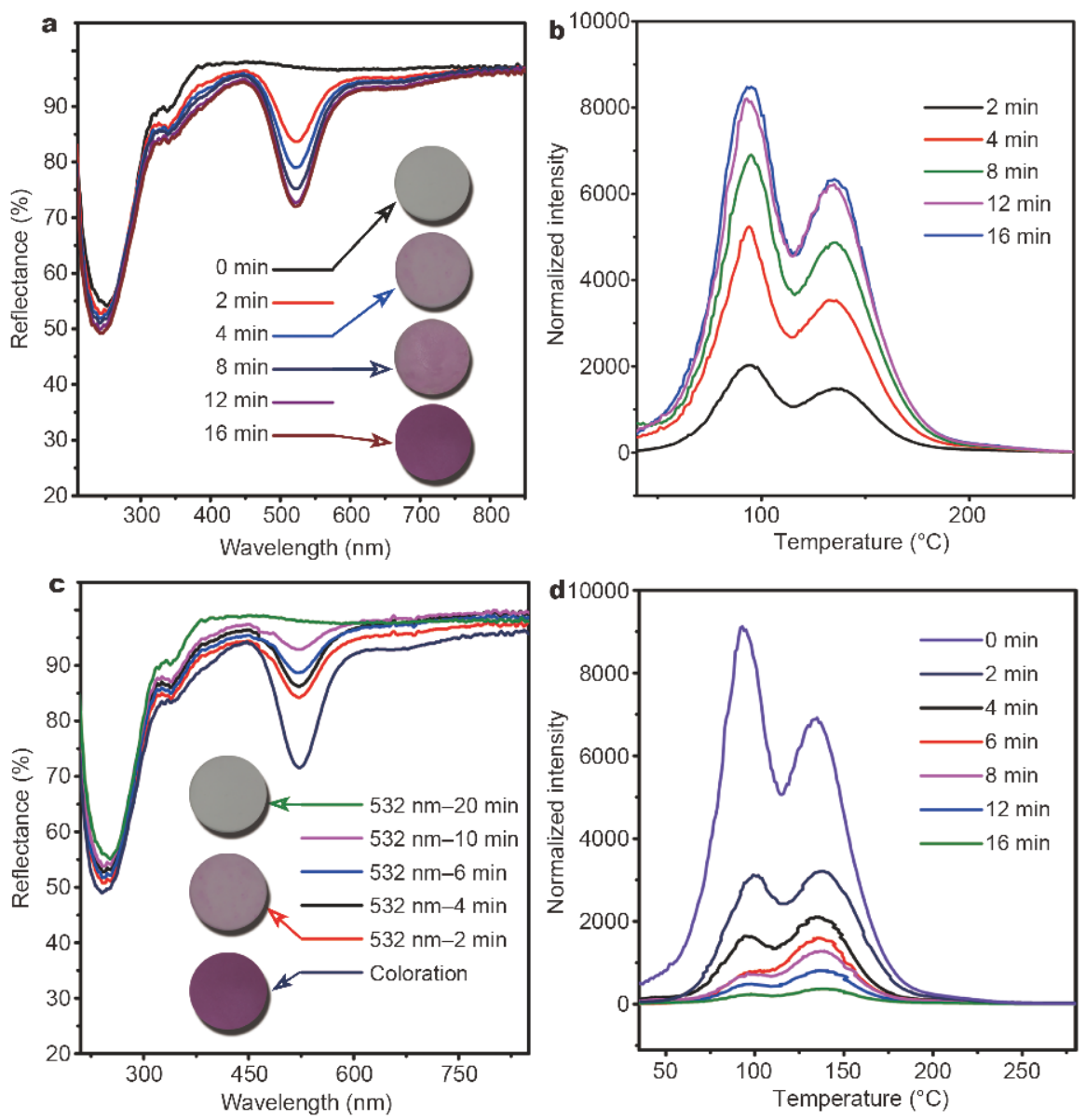

Figure 4 (a) Diffuse reflectance spectra and corresponding photographs, and (b) TL spectra of the BMSO-1350 upon the $254 \mathrm{~nm}$ light irradiation for various times; (c) the diffuse reflectance spectra and corresponding photographs, and (d) TL spectra of the pink BMSO-1350 irradiated with the $532 \mathrm{~nm}$ laser for various times.
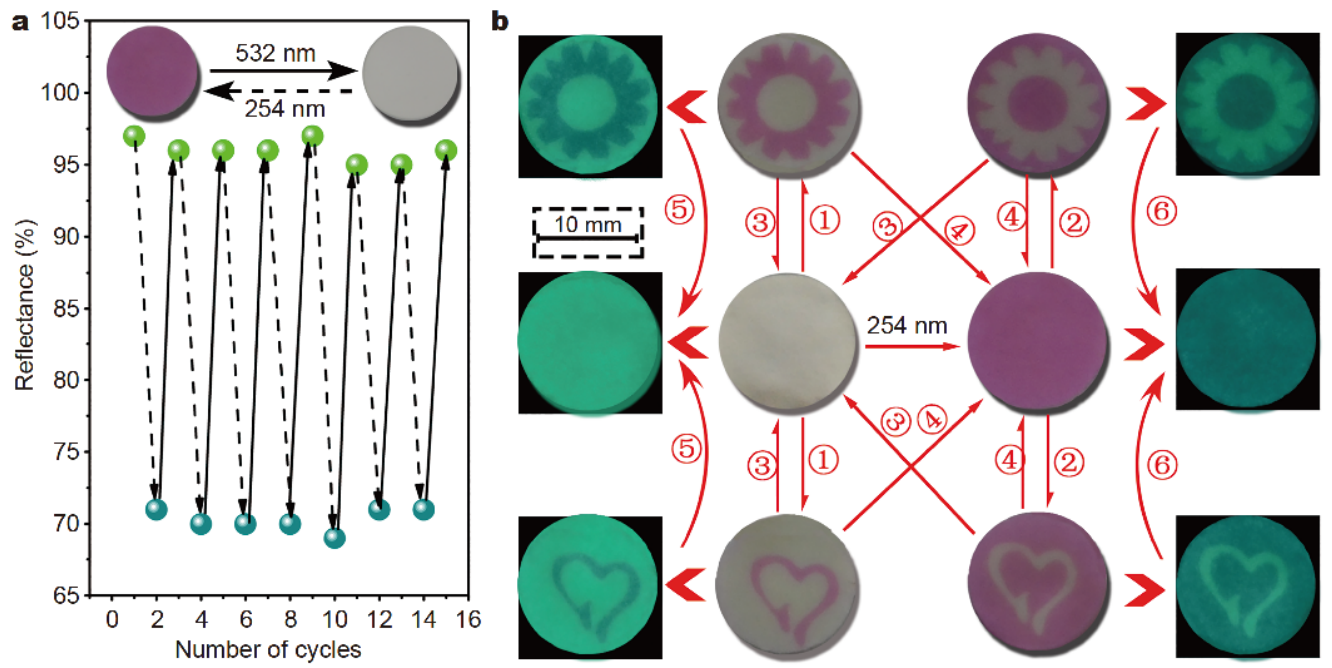

Figure 5 (a) Diffuse reflectance intensity of $520 \mathrm{~nm}$ in the BMSO-1350 ceramic upon alternating irradiation between the $254 \mathrm{~nm}$ light and the $532 \mathrm{~nm}$ laser as a function of the cycle numbers; (b) optical information recording and erasing of BMSO-1350 ceramic realized by using the $254 \mathrm{~nm}$ light and $532 \mathrm{~nm}$ laser irradiation, and the luminescence reading of optical information of BMSO-1350 ceramic upon the $365 \mathrm{~nm}$ excitation. 
pletely changed to pink under the irradiation with $254 \mathrm{~nm}$ light for $16 \mathrm{~min}$, the information recording can be performed by using the $532 \mathrm{~nm}$ laser to irradiate the surface of $\mathrm{BaMgSiO}_{4}: \mathrm{Bi}^{3+}$ ceramic with sunflower or heart masks. The information pattern with a pink background formed on the surface of the BMSO-1350 ceramic (Process (2)). When the pink region of the patterned ceramic was irradiated by using the $532 \mathrm{~nm}$ laser for $20 \mathrm{~min}$, the whole ceramic can be completely recovered to raw gray color, directly erasing the information (Process (3)). Similarly, when no photochromic region of BMSO-1350patterned ceramic was irradiated by $254 \mathrm{~nm}$ UV light for $16 \mathrm{~min}$, the color of the whole ceramic changed to pink, erasing the information (Process (4)). These results demonstrate that the dual-mode reversible optical information recording and erasing was performed, based on the reversible photochromic behavior of the $\mathrm{BaMgSiO}_{4}$ : $\mathrm{Bi}^{3+}$ ceramics.

The coloration and bleaching of $\mathrm{BaMgSiO}_{4}: \mathrm{Bi}^{3+}$ ceramics are dependent on the light stimulation time. Fig. S4a shows the four photochromic pink letters of "KUST" on the surface of the BMSO-1350 ceramic irradiated with the $254 \mathrm{~nm}$ light for $4,8,12$, and $16 \mathrm{~min}$, demonstrating the photochromic multiplexing. A similar multiplexing phenomenon was observed after the $532 \mathrm{~nm}$ laser bleaching for 2, 8, 14, and $20 \mathrm{~min}$, as shown in Fig. S4b. The multiplex photochromic and bleaching ability can be realized by changing the irradiation time using the 254 and $532 \mathrm{~nm}$ light, which could increase the optical storage capacity. Reversible luminescence information recording and reading-out of the $\mathrm{BaMgSiO}_{4}: \mathrm{Bi}^{3+}$ ceramics are based on the photochromic-induced reaction of luminescence modification.

The photochromic change from gray to pink of the BMSO-1350 was observed upon the $254 \mathrm{~nm}$ light irradiation, and the photochromic property was dependent on the irradiation time, as shown in Fig. 4a. The influence of the photochromic phenomenon on the photoluminescence of the BMSO-1350 ceramic was investigated. Fig. 6 a shows the luminescence spectra and the corresponding luminescence color change of the BMSO1350 ceramic upon the $254 \mathrm{~nm}$ light irradiation for $0,4,8$, 12 , and $16 \mathrm{~min}$. Under the $365 \mathrm{~nm}$ excitation, the BMSO1350 ceramics before and after the coloration exhibit a $510 \mathrm{~nm}$ luminescence peak of $\mathrm{Bi}^{3+}$. Apparently, the $510 \mathrm{~nm}$ luminescence of $\mathrm{Bi}^{3+}$ was modified by the photochromic reaction. After the $254 \mathrm{~nm}$ UV light-induced photochromism, the $510 \mathrm{~nm}$ luminescence of $\mathrm{Bi}^{3+} \mathrm{de}-$ creased with increasing time of the $254 \mathrm{~nm}$ light irradiation. This can be also identified by the luminescence image of BMSO-1350 ceramic, as exhibited in the inset of Fig. 6a. The modification degree of the $510 \mathrm{~nm}$ luminescence could be expressed by the $\Delta R_{n}$ value: $\Delta R_{n}=\left(R_{0}\right.$ $\left.-R_{n}\right) / R_{0} \times 100 \%$, where the $R_{n}$ and $R_{0}$ are the luminescence intensity of the photochromic BMSO-1350 ceramic and the luminescence intensity of the raw BMSO-1350 ceramic, respectively. The $\Delta R_{n}$ dependence on the $254 \mathrm{~nm}$ light irradiation time is displayed in Fig. 6b. The maximum modification degree of the $510 \mathrm{~nm}$ luminescence is about $65 \%$. The color center was generated in the BMSO1350 ceramic, as exhibited in the EPR spectra. After the photochromism, a $520 \mathrm{~nm}$ absorption band in the region of 450-600 nm was observed, which overlapped with the luminescence of $\mathrm{Bi}^{3+}$. The energy transfer may take place from the $\mathrm{Bi}^{3+}$ to the color centers, which can quench the luminescence of $\mathrm{Bi}^{3+}$. The energy transfer mechanism can be characterized by the decay lifetime of $\mathrm{Bi}^{3+}$.

Fig. 6c exhibits the decay curves of the BMSO-1350 ceramic at $510 \mathrm{~nm}$ after the $254 \mathrm{~nm}$ light irradiation for different times. The decay lifetime of $\mathrm{Bi}^{3+}$ has no significant change with an increasing irradiation time, indicating a radiative energy transfer from the $\mathrm{Bi}^{3+}$ to the color center. The pink BMSO-1350 ceramic can be completely bleached when irradiated with the $532 \mathrm{~nm}$ laser for $20 \mathrm{~min}$, as shown in Fig. 4c. The luminescence of the BMSO-1350 ceramic recovered to its initial state when bleached by $532 \mathrm{~nm}$ laser irradiation for $20 \mathrm{~min}$. Fig. S5 exhibits the luminescence spectra of the BMSO1350 ceramic upon alternation between the $254 \mathrm{~nm}$ irradiation for $16 \mathrm{~min}$ and $532 \mathrm{~nm}$ irradiation for $20 \mathrm{~min}$ as a function of cycle numbers. The $510 \mathrm{~nm}$ luminescence intensity of $\mathrm{Bi}^{3+}$ shows no degradation after seven cycles, and a good reversibility and reproducibility was demonstrated over several cycles. As shown in Fig. 6d, switching the states between "on" and "off" for the $\mathrm{Bi}^{3+}$ emission could be obtained.

The reversible behavior of photochromism was applied to fabricate the patterns on the surface of the $\mathrm{BaMgSiO}_{4}$ : $\mathrm{Bi}^{3+}$ ceramics, as shown in Fig. 5b. The information decoding could be realized by the $365 \mathrm{~nm}$ light to excite the BMSO-1350 ceramic with and without the photochromic patterns. The luminescence patterns are due to the emission color contrast in BMSO-1350 ceramic based on the photochromic reaction-induced luminescence modification, as shown in Fig. 5b. When the pink-patterned ceramic was irradiated by using $532 \mathrm{~nm}$ laser for $20 \mathrm{~min}$, the whole BMSO-1350 ceramic completely recovered to raw gray, and the luminescence erasing was realized upon the $365 \mathrm{~nm}$ excitation (Process (5)), as shown in Fig. 5b. When the gray patterns on the ceramic surface were ir- 

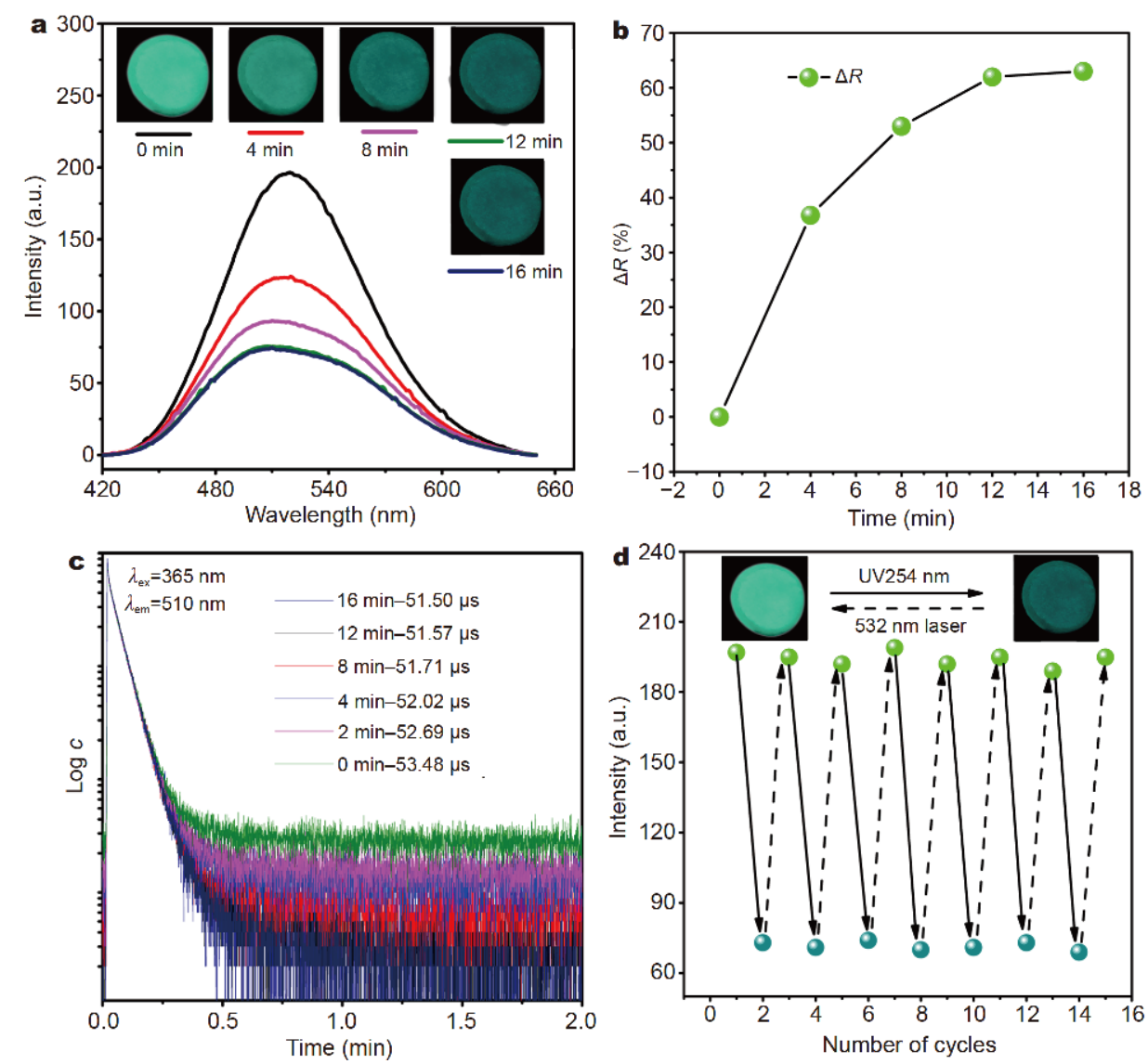

Figure 6 (a) Luminescence spectra and corresponding luminescence color change of the BMSO-1350 ceramic upon the $254 \mathrm{~nm}$ light irradiation for different times under the excitation of $365 \mathrm{~nm}$; (b) $\Delta R_{n}$ dependence on the $254 \mathrm{~nm}$ UV light irradiation time; (c) decay curves of the BMSO-1350 ceramic at $510 \mathrm{~nm}$ after the $254 \mathrm{~nm}$ light irradiation for different times; (d) $510 \mathrm{~nm}$ luminescence intensity of BMSO-1350 ceramic upon altering irradiation between $254 \mathrm{~nm}$ UV light and $532 \mathrm{~nm}$ laser as a function of the cycle number.

radiated with the $254 \mathrm{~nm}$ UV light for $16 \mathrm{~min}$, the entire BMSO-1350 ceramic changed to pink, causing the luminescence information to be erased upon the $365 \mathrm{~nm}$ excitation (Process (6)), as shown in Fig. 5b. In order to demonstrate a proof-of-concept of bit-by-bit optical writing and reading-out, the pink photochromic arrays were formed on the surface of the BMSO-1350 ceramic irradiated with the $254 \mathrm{~nm}$ light for $16 \mathrm{~min}$, as shown in Fig. 7a. When the color of BMSO-1350 ceramic completely changed to pink under irradiation with $254 \mathrm{~nm}$ light for $16 \mathrm{~min}$, the gray photochromic arrays were formed on the surface of the BMSO-1350 ceramic irradiated by the $532 \mathrm{~nm}$ light for $20 \mathrm{~min}$, as shown in Fig. 7a. Under the $365 \mathrm{~nm}$ UV light excitation, the pink photochromic points or the pink regions show weak green luminescence, while the gray points or regions emit more intense green light, as shown in Fig. 7a. The recorded information could be read-out "bit-by-bit" due to
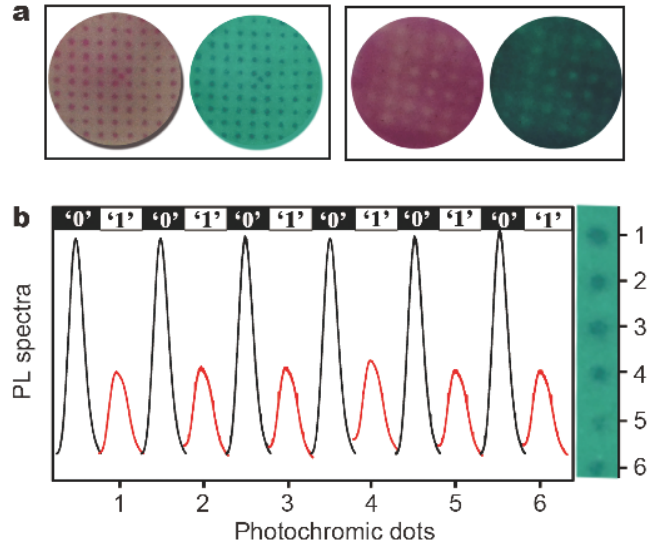

Figure 7 (a, left) pink and corresponding luminescence photos formed on the surface of the raw BMSO-1350 ceramic irradiated by the $254 \mathrm{~nm}$ light for $16 \mathrm{~min}$; (a, right) the gray arrays and corresponding luminescence photos formed on the surface of the pink BMSO-1350 ceramic irradiated by the $532 \mathrm{~nm}$ light for $20 \mathrm{~min}$; (b) optical information readout under the excitation of $365 \mathrm{~nm}$. 
the change in the luminescence intensity. As shown in Fig. $7 \mathrm{~b}$, the weak and intense luminescence corresponds to the binary states of " 0 " and " 1 ", respectively. These results indicate that the $\mathrm{BaMgSiO}_{4}: \mathrm{Bi}^{3+}$ ceramics may be available as an optical storage media. Previous investigations demonstrated that the optical storage dimension and density can be expanded by multiplexing the luminescence intensity through the adjustment of the excitation light power $[7,8,58]$. Fig. S4 shows the luminescence color change for 4 letters of "KUST" for various coloration and bleaching times on the surface of the BMSO-1350 ceramic, demonstrating the luminescence multiplexing. This luminescence multiplexing of BMSO1350 ceramic may further increase the optical data storage capacity as a multilevel optical medium.

\section{CONCLUSION}

In this study, a group of photochromic $\mathrm{BaMgSiO}_{4}: \mathrm{Bi}^{3+}$ ceramics were synthesized and their photoluminescence properties were investigated. The reversible color change between gray and pink was observed in the $\mathrm{BaMgSiO}_{4}$ : $\mathrm{Bi}^{3+}$ ceramics by alternating the radiation between $254 \mathrm{~nm}$ UV light and $532 \mathrm{~nm}$ laser. Based on the reversible photochromic behavior, the pink sunflower and heart patterns can be printed on the ceramic surface by $254 \mathrm{~nm}$ UV light; the same inverse patterns with the pink background can also be obtained upon $532 \mathrm{~nm}$ laser bleaching. The photoluminescence reversible modulation of the $\mathrm{BaMgSiO}_{4}: \mathrm{Bi}^{3+}$ ceramics was realized by the photochromic process, promoting the ability to read-out stored information of the $\mathrm{BaMgSiO}_{4}: \mathrm{Bi}^{3+}$ ceramics. The coloration and bleaching of $\mathrm{BaMgSiO}_{4}: \mathrm{Bi}^{3+}$ ceramics were dependent on the time of light stimulation, exhibiting the luminescence and photochromic multiplexing. This photoluminescence and photochromic multiplexing of the $\mathrm{BaMgSiO}_{4}: \mathrm{Bi}^{3+}$ ceramics may enhance the optical data storage capability.

Received 9 November 2019; accepted 4 December 2019; published online 14 January 2019

1 Tu M, Reinsch H, Rodríguez-Hermida S, et al. Reversible optical writing and data storage in an anthracene-loaded metal-organic framework. Angew Chem Int Ed, 2019, 58: 2423-2427

2 Gu M, Zhang Q, Lamon S. Nanomaterials for optical data storage. Nat Rev Mater, 2016, 1: 16070

3 Parthenopoulos DA, Rentzepis PM. Three-dimensional optical storage memory. Science, 1989, 245: 843-845

$4 \mathrm{Gu}$ M, Li X, Cao Y. Optical storage arrays: a perspective for future big data storage. Light Sci Appl, 2014, 3: e177

5 Riesen N, Pan X, Badek K, et al. Towards rewritable multilevel optical data storage in single nanocrystals. Opt Express, 2018, 26: 12266
6 Zuo Y, Xu X, Tao X, et al. A novel information storage and visual expression device based on mechanoluminescence. J Mater Chem C, 2019, 7: 4020-4025

7 Betzig E, Trautman JK, Wolfe R, et al. Near-field magneto-optics and high density data storage. Appl Phys Lett, 1992, 61: 142-144

8 Li L, Gattass RR, Gershgoren E, et al. Achieving lambda/20 resolution by one-color initiation and deactivation of polymerization. Science, 2009, 324: 910-913

9 Li W, Zhuang Y, Zheng P, et al. Tailoring trap depth and emission wavelength in $\mathrm{Y}_{3} \mathrm{Al}_{5-x} \mathrm{Ga}_{x} \mathrm{O}_{12}: \mathrm{Ce}^{3+}, \mathrm{V}^{3+}$ phosphor-in-glass films for optical information storage. ACS Appl Mater Interfaces, 2018, 10: 27150-27159

10 Zhuang Y, Wang L, Lv Y, et al. Optical data storage and multicolor emission readout on flexible films using deep-trap persistent luminescence materials. Adv Funct Mater, 2018, 28: 1705769

11 Long Z, Wen Y, Zhou J, et al. No-interference reading for optical information storage and ultra-multiple anti-counterfeiting applications by designing targeted recombination in charge carrier trapping phosphors. Adv Opt Mater, 2019, 7: 1900006

12 Lin S, Lin H, Huang Q, et al. Optical storage: A photostimulated $\mathrm{BaSi}_{2} \mathrm{O}_{5}: \mathrm{Eu}^{2+}, \mathrm{Nd}^{3+}$ phosphor-in-glass for erasable-rewritable optical storage medium. Laser Photonics Rev, 2019, 13: 1970022

13 Zhang Q, Zhang $\mathrm{Y}$, Sun $\mathrm{H}$, et al. Tunable luminescence contrast of $\mathrm{Na}_{0.5} \mathrm{Bi}_{4.5} \mathrm{Ti}_{4} \mathrm{O}_{15}: \operatorname{Re}(\mathrm{Re}=\mathrm{Sm}, \mathrm{Pr}, \mathrm{Er})$ photochromics by controlling the excitation energy of luminescent centers. ACS Appl Mater Interfaces, 2016, 8: 34581-34589

14 Ruan J, Yang Z, Huang A, et al. Thermomchromic reactioninduced reversible upconversion emission modulation for switching devices and tunable upconversion emission based on defect engineering of $\mathrm{WO}_{3}: \mathrm{Yb}^{3+}, \mathrm{Er}^{3+}$ phosphor. ACS Appl Mater Interfaces, 2018, 10: 14941-14947

15 Zhang Q, Sun H, Wang X, et al. Reversible luminescence modulation upon photochromic reactions in rare-earth doped ferroelectric oxides by in situ photoluminescence spectroscopy. ACS Appl Mater Interfaces, 2015, 7: 25289-25297

16 Pardo R, Zayat M, Levy D. Photochromic organic-inorganic hybrid materials. Chem Soc Rev, 2011, 40: 672

17 Zhang J, Zou Q, Tian H. Photochromic materials: more than meets the eye. Adv Mater, 2013, 25: 378-399

18 Yonezaki Y, Takei S. Photochromism and emission-color change in $\mathrm{Ba}_{3} \mathrm{MgSi}_{2} \mathrm{O}_{8}$-based phosphors. J Lumin, 2016, 173: 237-242

19 Jin Y, Hu Y, Fu Y, et al. Reversible colorless-cyan photochromism in $\mathrm{Eu}^{2+}$-doped $\mathrm{Sr}_{3} \mathrm{YNa}\left(\mathrm{PO}_{4}\right)_{3} \mathrm{~F}$ powders. J Mater Chem C, 2015, 3: 9435-9443

20 Suzuki K, Ubukata T, Yokoyama Y. Dual-mode fluorescence switching of photochromic bisthiazolylcoumarin. Chem Commun, 2012, 48: 765-767

21 Li M, Yang Z, Ren Y, et al. Reversible modulated upconversion luminescence of $\mathrm{MoO}_{3}: \mathrm{Yb}^{3+}, \mathrm{Er}^{3+}$ thermochromic phosphor for switching devices. Inorg Chem, 2019, 58: 6950-6958

22 Hou Y, Du J, Hou J, et al. Rewritable optical data storage based on mechanochromic fluorescence materials with aggregation-induced emission. Dyes Pigments, 2019, 160: 830-838

23 Zhang $\mathrm{Y}$, Luo L, Li K, et al. Up-conversion luminescence switching of $\left(\mathrm{K}_{0.5} \mathrm{Na}_{0.5}\right)_{0.995} \mathrm{Er}_{0.005} \mathrm{NbO}_{3}$ ferroelectric ceramic based on photochromic reaction. Ceramics Int, 2018, 44: 1086-1090

24 Li P, Yang X, Maß TWW, et al. Reversible optical switching of highly confined phonon-polaritons with an ultrathin phasechange material. Nat Mater, 2016, 15: 870-875

25 Qin B, Chen H, Liang H, et al. Reversible photoswitchable fluor- 
escence in thin films of inorganic nanoparticle and polyoxometalate assemblies. J Am Chem Soc, 2010, 132: 2886-2888 readout in $\mathrm{Er} / \mathrm{Yb}$ co-doped $\mathrm{Na}_{0.5} \mathrm{Bi}_{2.5} \mathrm{Nb}_{2} \mathrm{O}_{9}$-based optical storage materials for optical data storage device applications. J Mater Chem C, 2017, 5: 3838-3847

27 Ouyang X, Xu Y, Feng Z, et al. Polychromatic and polarized multilevel optical data storage. Nanoscale, 2019, 11: 2447-2452

28 Zijlstra P, Chon JWM, Gu M. Five-dimensional optical recording mediated by surface plasmons in gold nanorods. Nature, 2009, 459: $410-413$

29 Ren H, Li X, Zhang Q, et al. On-chip noninterference angular momentum multiplexing of broadband light. Science, 2016, 352: 805-809

30 Li C, Yan H, Zhang GF, et al. Photocontrolled intramolecular charge/energy transfer and fluorescence switching of tetraphenylethene-dithienylethene-perylenemonoimide triad with donor-bridge-acceptor structure. Chem Asian J, 2014, 9: 104-109

31 Ko CC, Yam VWW. Coordination compounds with photochromic ligands: Ready tunability and visible light-sensitized photochromism. Acc Chem Res, 2018, 51: 149-159

32 Bisoyi HK, Li Q. Light-driven liquid crystalline materials: from photo-induced phase transitions and property modulations to applications. Chem Rev, 2016, 116: 15089-15166

33 Rameshbabu K, Zou L, Kim C, et al. Self-organized photochromic dithienylcyclopentene organogels. J Mater Chem, 2011, 21: 15673

34 Tian H, Chen B, Tu HY, et al. Novel bisthienylethene-based photochromic tetraazaporphyrin with photoregulating luminescence. Adv Mater, 2002, 14: 918

35 Denekamp C, Feringa BL. Optically active diarylethenes for multimode photoswitching between liquid-crystalline phases. Adv Mater, 1998, 10: 1080-1082

36 Irie M. Diarylethenes for memories and switches. Chem Rev, 2000, 100: $1685-1716$

37 Mamiya J, Kuriyama A, Yokota N, et al. Photomobile polymer materials: Photoresponsive behavior of cross-linked liquid-crystalline polymers with mesomorphic diarylethenes. Chem Eur J, 2015, 21: 3174-3177

38 Wang J, Gao Y, Zhang J, et al. Invisible photochromism and optical anti-counterfeiting based on D-A type inverse diarylethene. J Mater Chem C, 2017, 5: 4571-4577

39 Jin Y, Hu Y, Yuan L, et al. Multifunctional near-infrared emitting $\mathrm{Cr}^{3+}$-doped $\mathrm{Mg}_{4} \mathrm{Ga}_{8} \mathrm{Ge}_{2} \mathrm{O}_{20}$ particles with long persistent and photostimulated persistent luminescence, and photochromic properties. J Mater Chem C, 2016, 4: 6614-6625

40 Yamase T. Photo- and electrochromism of polyoxometalates and related materials. Chem Rev, 1998, 98: 307-326

41 Sun $\mathrm{H}$, Liu J, Wang $\mathrm{X}$, et al. (K,Na) $\mathrm{NbO}_{3}$ ferroelectrics: a new class of solid-state photochromic materials with reversible luminescence switching behavior. J Mater Chem C, 2017, 5: 9080-9087

42 Zhang JC, Qin QS, Yu MH, et al. Up-conversion photostimulated luminescence of $\mathrm{Mg}_{2} \mathrm{SnO}_{4}$ for optical storage. Chin Phys Lett, 2011, 28: 027802

43 Kamimura S, Yamada $\mathrm{H}, \mathrm{Xu}$ CN. Purple photochromism in $\mathrm{Sr}_{2} \mathrm{SnO}_{4}: \mathrm{Eu}^{3+}$ with layered perovskite-related structure. Appl Phys Lett, 2013, 102: 031110

44 Zhang Y, Luo L, Li K, et al. Reversible up-conversion luminescence modulation based on UV-VIS light-controlled photochromism in $\mathrm{Er}^{3+}$ doped $\mathrm{Sr}_{2} \mathrm{SnO}_{4}$. J Mater Chem C, 2018, 6: 13148-13156
45 Wang S, Fan W, Liu Z, et al. Advances on tungsten oxide based photochromic materials: Strategies to improve their photochromic properties. J Mater Chem C, 2018, 6: 191-212

46 Mellerup SK, Wang S. Isomerization and rearrangement of boriranes: from chemical rarities to functional materials. Sci China Mater, 2018, 61: 1249-1256

47 Nishio S, Kakihana M. Evidence for visible light photochromism of $\mathrm{V}_{2} \mathrm{O}_{5}$. Chem Mater, 2002, 14: 3730-3733

48 Li K, Luo L, Zhang $\mathrm{Y}$, et al. The upconversion luminescence modulation and its enhancement in $\mathrm{Er}^{3+}$-doped $\mathrm{Na}_{0.5} \mathrm{Bi}_{0.5} \mathrm{TiO}_{3}$ based on photochromic reaction. J Am Ceram Soc, 2018, 101: 5640-5650

49 Yang F, Jia B, Wei T, et al. Reversible regulation of upconversion luminescence in new photochromic ferroelectric materials: $\mathrm{Bi}_{4-x} \mathrm{Er}_{x} \mathrm{Ti}_{3} \mathrm{O}_{12}$ ceramics. Inorg Chem Front, 2019, 6: 2756-2766

50 Wales DJ, Cao Q, Kastner K, et al. 3D-printable photochromic molecular materials for reversible information storage. Adv Mater, 2018, 30: 1800159

51 Veber A, Cicconi MR, Puri A, et al. Optical properties and bismuth redox in Bi-doped high-silica Al-Si glasses. J Phys Chem C, 2018, 122: $19777-19792$

52 Tsiumra V, Zhyshkovych A, Malyi T, et al. Localized exciton luminescence in $\mathrm{YVO}_{4}: \mathrm{Bi}^{3+}$. Optical Mater, 2019, 89: 480-487

53 Zhou S, Jiang N, Zhu B, et al. Multifunctional bismuth-doped nanoporous silica glass: From blue-green, orange, red, and white light sources to ultra-broadband infrared amplifiers. Adv Funct Mater, 2008, 18: 1407-1413

54 Huang A, Yang Z, Yu C, et al. Near-infrared quantum cutting luminescence and energy transfer mechanism of $\mathrm{Ba}_{2} \mathrm{Y}\left(\mathrm{BO}_{3}\right)_{2} \mathrm{Cl}$ : $\mathrm{Bi}^{3+}, \mathrm{Yb}^{3+}$ phosphors. IEEE Photonics J, 2018, 10: 1-7

55 Vtyurina DN, Eistrikh-Geller PA, Kuz'micheva GM, et al. Influence of monovalent $\mathrm{Bi}^{+}$doping on real composition, point defects, and photoluminescence in $\mathrm{TlCdCl}_{3}$ and $\mathrm{TlCdI}_{3}$ single crystals. Sci China Mater, 2017, 60: 1253-1263

56 Wang D, Liu W, Zhang Z. Emission tuning studies in $\mathrm{BaMgSiO}_{4}$ : $\mathrm{RE}\left(\mathrm{RE}=\mathrm{Eu}^{2+}, \mathrm{Sr}^{2+}\right)$ for white LEDs. Mater Chem Phys, 2018, 207: $479-488$

57 Zhang G, Zhao L, Fan F, et al. Near UV-pumped yellow-emitting $\mathrm{Ca}_{3} \mathrm{TeO}_{6}: \mathrm{Dy}^{3+}$ phosphor for white light-emitting diodes. SpectroChim Acta Part A-Mol Biomol Spectr, 2019, 223: 117343

58 Ren Y, Yang Z, Li M, et al. Reversible upconversion luminescence modification based on photochromism in $\mathrm{BaMgSiO}_{4}: \mathrm{Yb}^{3+}, \mathrm{Tb}^{3+}$ ceramics for anti-counterfeiting applications. Adv Opt Mater, 2019, 7: 1900213

Acknowledgements This work was supported by the National Natural Science Foundation of China $(51762029,11674137)$ and the Applied Basic Research Key Program of Yunnan Province (2018FA026).

Author contributions Yang $\mathrm{Z}$ and $\mathrm{Yu} J$ supervised the project. Ren $\mathrm{Y}$ designed and performed the experiments. Qiu J, Wang Y, Li M, Song Z, Ullah A, and Khan I participated in analyzing and interpreting the data. All authors contributed to the general discussion.

Conflict of interest The authors declare that they have no conflict of interest.

Supplementary information online version of the paper.
Supporting data are available in the 


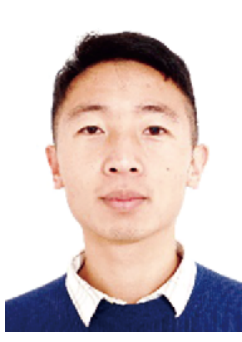

Youtao Ren is currently pursuing his Master's degree from Kunming University of Science and Technology under the supervision of Prof. Zhengwen Yang. His current work focuses on the fabrication of photochromic ceramics for optical storage applications.

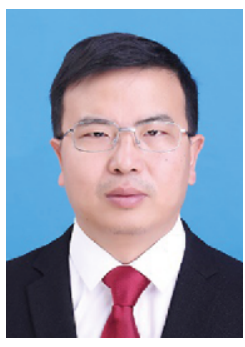

Zhengwen Yang is currently a professor of the College of Materials Science and Engineering in Kunming University of Science and Technology. He received his Bachelor's degree in 2002, Master's degree in 2005 from Jilin University, and his $\mathrm{PhD}$ degree from Tsinghua University in 2009. His research interests are the modification and enhancement of the up-conversion luminescence.
基于光致变色效应的 $\mathrm{BaMgSiO}_{4}: \mathrm{Bi}^{3+}$ 陶瓷的发光性 质调控及信息的可逆写入、擦除和读出研究

任友涛, 杨正文 ${ }^{1^{*}}$, 王悦辉 ${ }^{2}$, 李明骏 ${ }^{1}$, 邱建备 ${ }^{1}$, 宋志国 ${ }^{1}$, 余杰 ${ }^{1 *}$, Asad Ullah ${ }^{1}$, Imran Khan ${ }^{1}$

摘要 光存储技术与传统固态存储和磁存储相比有许多优点, 如成 本低、可重复性存储. 因此, 光存储的需求正在持续增长. 本文研究 了铋掺杂的硅酸镁钡陶瓷的光致变色及光致发光现象. 在紫外线 $(254 \mathrm{~nm})$ 和 $532 \mathrm{~nm}$ 激光交替辐照下, 实现了陶瓷在灰色与粉红色 之间的可逆转变. 研究证实 $\mathrm{MgSiO}_{4}: \mathrm{Bi}^{3+}$ 陶瓷的可逆光致变色来源 于基质中的氧空位陷阴对电子的俘获和释放. 基于可逆光致变色 效应在陶瓷表面制作不同颜色的图案, 实现了光信号的双模式存 储和擦除. 同时, 在光致变色过程中实现了光致发光的可逆调控; 通过这种可逆的发光调控行为, 实现存储信息的读出; 此外, 变色 和漂白的程度与光照射时间有关, 因此可实现多通路编码存储, 有 望提高光存储容量. 